On the other hand, if facilities are continually denied the general practitioner for the ordinary care that he is trained to provide, his job satisfaction will also deteriorate. The quality of any medical care is directly related to the satisfaction a doctor has from managing the diagnostic work-up and treatment as much as he is capable from training and experience. The less satisfaction derived from any job, the poorer will be the quality of work.

Today initial contact a patient makes with the medical care services is made in the community, since most problems brought to a general practitioner do not need the facilities of a medical centre. This is so for economic reasons as well as being true medically. Who will do this job if more of the job satisfaction of general practice is given up or assumed by the hospital service?

THEODORE I JONES

Salen, Isle of Mull

\section{TRAB test}

SIR,-The report by Scrutator (3 July, p 57) states that "the standard is related to that expected of a British qualified doctor who has completed the preregistration year and been granted full registration." This was the terminology used by the Overseas Committee of the General Medical Council, and, although I approved that committee's belated conversion to my campaign for a test for overseas doctors, I felt that the term "related to" was unsatisfactory.

It was my last appearance as a member of the General Medical Council in June 1975, and I said that I knew of only two kinds of relations, rich relations and poor relations, and that with the protracted conversion of the General Medical Council to hold a test at all it was highly likely that the TRAB test would become a poor relation of the standard of a graduate from a British medical school. I suggested we use a term which was more explicit and which could be checked and proposed that "equivalent to" be substituted for "related to". Sir John Richardson, the president, said he thought this was a reasonable amendment which he could accept and this was confirmed by representatives of the Overseas Committee and the council in general.

I hope that there has been no going back on this decision, for things could well deteriorate to any "related" level that was thought to be expedient. If Scrutator is mistaken he should make this clear; if not, then the elected members of the council have urgent work on their hands.

Myre SiM

Department of Psychiatry

University of Ottawa, Ontario, Canada

***Scrutator says that the phrase which Professor Myre Sim criticises was taken from the fourth report of the Temporary Registration Assessment Board.-ED, BMF.

\section{Compelling needs of our hospitals}

SIR,-Dr M Elderkin (9 October, p 864) thinks it absurd that half of the new graduates in medicine will soon be women when so few women doctors continue in full-time work and many give up medicine altogether. It is unfortunate that a consultant should make such a Victorian suggestion to the Royal Commission.
It seems reasonable to think that there is an equal distribution of aptitude and ability for a career in medicine between the sexes. As one who is still battling with the intricacies of HM 69/6 I find that the absurdity lies in system which is unable to provide part-time training posts in suitable specialties. Children can occupy a relatively short period in the working life of a woman, and it is only at this time that a full-time commitment may not be possible. Why should able women be deprived of a fulfilling career, or indeed why should the community be deprived of their skills?

London SW15

Christine LeE

SIR,-Dr M Elderkin (9 October, p 864) gives further currency to the myth about "disparities between the ... career earnings of hospital doctors and general practitioners . . already interfering with recruitment into the specialties." According to Dr J A Muir Gray ${ }^{1}$ the number of consultants in England and Wales increased by $68 \%$ between 1959 and 1973 , the number of senior registrars by $95 \%$, the number of registrars by $58 \%$, and the population by $7 \%$, but the number of GPs diminished by $3 \%$ during the same period

Maldon, Essex

David Cargill

${ }^{1}$ Gray, J A M, World Medicine, 1976, 12, 55

\section{Smoking and genitourinary infection}

SIR,-In undertaking a systematic study of patients attending the subfertility clinic run by one of us (GD) the opportunity arose to include a section in the questionnaire concerning smoking habits. Patients were asked as a matter of routine whether they had any history of genitourinary infection (GUI). In all, from April 1973 to December 1975, 3074 subjects had attended the clinic, their mean age being 30.5 years ( $S D=5.6$ years). When classified according to their smoking habits it appeared (see table) that GUI had occurred with the same frequency among light and medium smokers as among non-smokers, but that the proportion of GUI cases was higher for the heavy smokers and much more so for the very heavy smokers. The percentage GUI was also found to be higher among the exsmokers but in general these had ceased to smoke recently and after the period of infection. These differences remained highly significant when the GUI rate was standardised for age. When the type of infection involved was taken into consideration, it was found that the effect could be attributed to the cases of urethritis, which accounted for $59 \%$ of the infections reported and in $72 \%$ of which gonorrhoea had been mentioned explicitly.

The more frequent occurrence of urethritis among heavy smokers could be due simply to a difference in sexual behaviour. However, the considerable and regular increase observed in the rate of GUI with the quantity smoked implies rather that there may be a biological explanation. Transmission of infection following a single exposure to risk depends on several factors, among which individual susceptibility has been cited, and may be related to the subject's immune response potential. ${ }^{1}$ In addition animal experimentation has demonstrated that cigarette smoke and its derivatives have an immunosuppressive effect on the humoral $^{2} 3$ and cellular ${ }^{4}$ responses.

The fact that the risk of GUI is increased only for the heavy smokers resembles closely the observations of Schmauz and $\mathrm{Cole}^{5}$, who reported finding that the risk of cancer of the renal pelvis or ureter is increased only at very high levels of tobacco consumption, whereas the risk of bladder cancer is increased for all smokers. They suggest that this difference may be due to the rapid transit of urine through the former organs as opposed to storage in the latter.

A BOYCE D SCHWARTZ

Unité de Recherches Statistiques de l'INSERM, 16bis, avenue Paul-Vaillant-Couturier,
94800-Villejuif-France

Laboratoire d'Histologie-EmbryologieCytogénétique,

Centre Hospitalier de Bicêtre,

78, avenue du Général Leclerc,

${ }^{1}$ Holmes, $\mathrm{K} \mathrm{K}$, Johnson, D W, and Trostle, $\mathrm{H} \mathrm{J}$, American fournal of Epidemiology, 1970, 91, 170.
Thomas, W, Holt, P G, and Keast, D, Nature, 1973, 243, 240.

soszman, T L, and Rogers, A S, American Review of Respiratory Diseases, 1973, 108, 1158.

Chalmer, J, Holt, P G, and Keast, D, fournal of the National Cancer Institute, 1975, 55, 1129.

Schmauz, R, and Cole, P, fournal of the National Cancer Institute, 1974, 52, 1431.

\section{Referred itch}

SIR,-Referring to Dr P R Evans (9 October, p 839), this syndrome is not confined to the skin. One of my patients assures me that he regularly observes that, when he lies quietly in bed with his eyes closed and there occurs a sudden unexpected noise, he sees a blinding flash all over the visual field. This does not occur if he expects a noise or if he concentrates, waiting for one. It does not seem to matter how strong the noise is so long as it is unexpected. The visual flash seems to be elicited in the form of a trigger reaction. I can assure you that this observation comes from an entirely reliable patient.

E ELKaN

Pinner, Middlesex

\section{Hairy legs}

SIR,-Your leading article on this subject (2 October, p 777), while covering the conventional methods of treating excessive hair growth, makes no mention of the use of cyproterone acetate, an antiandrogen with marked progestational effects. Extensive

Occurrence of past infection according to smoking status

\begin{tabular}{|c|c|c|c|c|c|c|c|c|}
\hline \multirow{2}{*}{$\frac{\text { Smoking status }}{\text { g/day: }}$} & \multirow{2}{*}{$\frac{\text { Non-smoker }}{-}$} & \multicolumn{5}{|c|}{ Smoker } & \multirow{2}{*}{$\frac{\text { Ex-smoker }}{-}$} & \multirow{2}{*}{$\begin{array}{c}\text { Significance } \\
\left(x^{2}, 6 \mathrm{df}\right)\end{array}$} \\
\hline & & $1-9$ & $10-19$ & $20-29$ & $30-39$ & $\geqslant 40$ & & \\
\hline $\begin{array}{ll}\text { No of patients } & \ldots \\
\% \text { GUI } & \ldots \\
\% \text { Urethritis } & \ldots\end{array}$ & $\begin{array}{r}793 \\
13 \cdot 0 \\
7 \cdot 4\end{array}$ & $\begin{array}{r}404 \\
14 \cdot 6 \\
7 \cdot 9\end{array}$ & $\begin{array}{r}586 \\
13 \cdot 1 \\
7 \cdot 3\end{array}$ & $\begin{array}{r}715 \\
16 \cdot 6 \\
9 \cdot 9\end{array}$ & $\begin{array}{l}162 \\
24 \cdot 7 \\
13 \cdot 6\end{array}$ & $\begin{array}{r}113 \\
30 \cdot 1 \\
22 \cdot 1\end{array}$ & $\begin{array}{c}301 \\
18 \cdot 3 \\
10 \cdot 3\end{array}$ & $\begin{array}{l}\mathbf{P}<\overline{10^{-5}} \\
\mathbf{P}<10^{-5}\end{array}$ \\
\hline
\end{tabular}


experience in the use of this drug for this condition in almost 400 patients has been reported by Hammerstein et $a l^{1}$ and they noted significant improvement in hirsuties in the majority of cases. They recommend a "reverse sequential" regimen using a dose of $100 \mathrm{mg}$ of cyproterone acetate on days $5-14$ of the cycle, combined with $50 \mu \mathrm{g}$ of ethinyl oestradiol on days 5-25. The latter drug is added for cycle control and certain contraception.

Using this regimen we have demonstrated a marked reduction in the rate of growth as well as the diameter of the individual hairs. ${ }^{2}$ Beneficial results with this drug have also been reported by Barnes et al. ${ }^{3}$

The drug is primarily a competitive inhibitor of androgens at the receptor level, ${ }^{4}$ but it also inhibits steroid synthesis. ${ }^{5}$ Because of this effect caution is necessary in its use, and adrenal insufficiency has been reported in children being treated for precocious puberty. ${ }^{6}$ However, the study by Hammerstein et al found no evidence of adrenal impairment.

Your comments on women's attitude to excessive body hair are more optimistic than our current experience indicates and perhaps rather flippant. We have found that, although the condition is not serious medically, these women are extremely anxious and agitated by their condition, sometimes seeking psychiatric assistance. Certainly the necessity for frequent shaving is very distressing to them. Their mood dramatically changes, however, when they can see the benefits from the treatment.

ADRIAN K THOMAS

Department of Obstetrics and Gynaecology,
University of Sheffield

'Hammerstein, J, et al, Fournal of Steroid Biochemistry, 'Hammerstein,

'Thomas, A K, Ebling, F J, and Cooke, I D, British Fournal of Obstetrics and Gynaecology, in press.

Barnes, E W, et al, Clinical Endocrinology, 1975, 4, 65 Neumann, F, and Graf, K-J, Journal of International Medical Research, 1975, 3, supplement (4) 1 .

Panesar, N S, and Stitch, S R, fournal of Endocrinology, 1976, 69, 3, 14P.

crinology, 1976, 69, 3, $13 \mathrm{P}$.

\section{Art of general practice}

SIR,-May I welcome your new series "Clinics in General Practice." The consultant's comments were excellent and succinctly made. The trainer, with reference to diarrhoea and pyrexia, has missed the teaching point of the case. The art of general practice is to remember that "common things are common," but the wise GP keeps the small print diagnosis up his sleeve. In small children one of the more common causes of diarrhoea and pyrexia is upper respiratory infection. One of the rarer (besides intestinal infections of salmonella nature) is appendicitis.

DeREK A COFFMAN

Wembley,

Middlesex

\section{Reliable detection of ruptured membranes}

SIR,-Many antenatal patients are hospitalised because of doubt as to whether there has been a spontaneous leak of liquor. Furthermore, their management as regards early delivery may also depend on the definitive knowledge as to whether the membranes are intact. Tests to differentiate between the alkalinity of liquor and the acidity of vaginal fluid and urine were described in the 1930s. ${ }^{12}$ However, our inquiries suggest that few obstetricians use such tests and many were unaware of them. We have therefore carried out a study of the efficacy of sterile nitrazine yellow-coated swabs mounted on sticks (Medical Wire and Equipment Co (Bath) Ltd). These swabs indicate a change to an alkaline $\mathrm{pH}$ by turning blue when even a small amount of liquor is present at the external cervical os.

A correct positive result was obtained in 75 patients whose membranes had been ruptured artificially one to four hours earlier and a correct negative result was obtained in 74 patients who were swabbed at the antenatal clinic during the third trimester. In one further antenatal patient a negative result was obtained during premature labour, but the membranes were found to be clinically ruptured 48 hours later. Other swabs were taken from patients with blood (13) and meconium (8) stained liquor, and a positive result was still obtained. Swabs from antenatal and gynaecological patients with proved trichomonal or monilial vaginitis did not give clinically false results. Lastly, vaginal swabs were taken in the presence of Hibitane cream, Hibitane solution, and $\mathrm{KY}$ jelly, and again clinically false results were not obtained.

We believe that nitrazine yellow swabs provide a very cheap and effective way of differentiating a leak of liquor from urine or vaginal discharge. We recommend a cervical swab taken by a sterile technique rather than a low vaginal swab, as it is possible that contamination of the lower vagina with urine (which occasionally is alkaline) may give a false positive result, and similarly a low vaginal swab may miss small amounts of liquor at the cervix.

E SKLOVSKY Clinical assistant

\section{A H MacLennan} Lecturer

Nuffield Department of Obstetrics and Gynaecology, John Radic

${ }^{1}$ Berlind, M M, American Fournal of Obstetrics and Gynecology, 1932, 24, 198.
King, A G, American Journal of Obstetrics and
Gynecology, 1935, 30, 860.

\section{Curry kidney}

SIR,-I was most interested to read your leading article on the curry kidney (10 July, p 69). You observed on the basis of the two small studies that in Fiji the Indians are "virtually the only sufferers from stones." Further, you suggested that the similarity between the ingredients in Worcestershire sauce and curry may be the clue to the pathogenesis of renal stones. Singapore is a mixed ethnic community with a significant proportion of curry-consuming Indians. A recent study of 254 hospital patients of the different ethnic groups resident in Singapore, ${ }^{1}$ including Indians from different parts of India, failed to demonstrate any statistically significant increase in the incidence of renal calculi among Indians.

There were 49 Indians, 177 Chinese, 24 Malays, and 4 other patients in the study. Indians accounted for $19.3 \%$ of the patients seen while they constituted $7 \cdot 0 \%$ of the population of Singapore. The apparent increase is explained by the fact that the hospital utilisation figures showed that Indians constitute $14.3 \%$ of patients seen. Furthermore, the age and sex distribution of the Indian population in Singapore is peculiar. There is a preponderance of Indian males in the 20 to 59 age group in the population. This is the population at increased risk of renal stone disease. ${ }^{2}$

Multiethnic communities are interesting sources of epidemiological information, but enthusiasm in interpretation of small numbers studied has to be tempered by a statistical analysis which takes in important variables. While curries and Worcestershire sauce may continue to spice the aetiology of renal stone disease, the meat of the matter still escapes our notice.

Singapore General Hospital

J A TAMBYAH

'Tambyah, J A, et al, Singapore Medical fournal, 1972,
6, 269.
2avan, J N, et al, Medical fournal of Australia, 1971,
2, 1049.

\section{Hazard of glutethimide}

SIR,-A patient with osteomalacia was referred by $\operatorname{Dr} G R$ Clarke when working in this department for further investigation in the department of metabolic diseases. She was detected as having hepatic enzyme induction leading to rapid vitamin $\mathrm{D}$ destruction caused by prolonged glutethimide administration. ${ }^{1}$ This hazard had not been previously reported but is an additional contraindication to prolonged administration of glutethimide and possibly barbiturates not mentioned in your leading article (12 June, $\mathrm{p}$ 1424).

J A Mathews D A H YATES Department of Rheumatology,
St Thomas's Hospital,

' Greenwood, R H, Prunty, F T G, and Silver, J, British Medical fournal, 1973, 195, 643 .

\section{Hormonal pregnancy tests and} congenital malformations

SIR,-According to a reliable medical source some general practitioners are still using hormonal pregnancy tests despite the warning notice issued last year by the Committee on Safety of Medicines. ${ }^{1}$ In view of the possible fetal damage which might be induced with this method of pregnancy diagnosis ${ }^{2-4}$ the information requires thorough checking-even if it is based on hearsay evidence. This practice may have arisen from certain confusing factors.

The warning notice referred to 12 different preparations which were used for pregnancy testing, of which only Primodos and Norlestrin are available at present. The former product (manufactured by Scherings Chemicals, Ltd) has been recognised primarily for pregnancy testing, and proved to be very popular, ${ }^{2}$ whereas the latter one (a Parke-Davis product) had the reputation of being an oral contraceptive and was less frequently used for diagnostic purposes. These products are now recommended for the symptomatic treatment of secondary amenorrhoea, and the manufacturers' data sheets have been revised accordingly. ${ }^{5}$

The fact that these two products remained on the market while the others were withdrawn may formulate false confidence. The warning remarks on the adverse effect in pregnancy, 